\title{
DESIGN AND EVALUATION OF A CONTROLLER TO ACHIEVE OPTIMUM SEEDING RATE WITH SPECIFIC SPATIAL MANAGEMENT IN AGRICULTURAL MACHINERY
}

\author{
A. Saberi ${ }^{1 *}$, E. Khesali ${ }^{2}$, M. Fakhri $^{3}$, H. Enayati ${ }^{4}$, M. Koushapoor ${ }^{5}$ \\ ${ }^{1}$ Dept. of Electrical Control Engineering, Islamic Azad University, Science and Research Branch, Tehran, Iran - \\ arman.saberi.ngo@gmail.com \\ ${ }^{2}$ Dept. of Photogrammetry and Remote Sensing, K. N. Toosi University of technology, Tehran, Iran - elahe.khesali@mail.kntu.ac.ir \\ ${ }^{3}$ Faculty of Strategic Management, Supreme National Defense University, Tehran, Iran - m.fakhri@ chmail.ir \\ ${ }^{4}$ Dept. of Photogrammetry and Remote Sensing, K. N. Toosi University of technology, Tehran, Iran - en.hamid22@gmail.com \\ ${ }^{5}$ Faculty of Geodesy and Geomatics Engineering, Islamic Azad University, Science and Research Branch, Shahroud, Iran - \\ m.koosha54@gmail.com
}

KEY WORDS: Geographic information, Positioning, Navigation, DC engine, seed drill, Controller

\begin{abstract}
:
Achieving optimal seeding rates in different areas of the field is very important for maximizing crop yield. Nowadays, spatial management of croplands as a modern technology has been recommended in precision agriculture systems. Agricultural inputs such as seed, fertilizers, herbicides, etc., should be optimized with field conditions in different areas. For example, fertilizing and moisture should being compatible. Due to changes in these two factors, optimum seeding rates might being different in a field; areas with higher fertility or higher soil moisture have the higher seed rates. An applicable method to reach the ability of variable seeding rates in agricultural machines is to add controllers to the conventional fixed seeding rate seed drills. In the spatial management technology for seeding in a variable rate, first, the map of required seed for seeding practice is prepared for each particle of the field and then loaded in the machine at GIS format. The controller controls the seed rate continuously using the GIS map and the spatial position of the machine at field is provided by positioning systems. The aim of this study was to select the best closed-loop variable rate control system for Hassia seed drill shifting from a fixed rate to variable rate. To this end, Assessment of the performance of a control system that mounted on the seed dill and vary the rotational speed of the seed metering drive shaft performed. The control system was included a 250-watt DC engine, gearbox with constant gear ratio, two encoders (first for sensing the seed drill speed and second for sensing the rotational speed of the engine), position receiver and navigation, DC engine controller, and a portable computer for collecting data. The response time for transmitting seeding rate by the controller was determined from low to high $4 / 7$ seconds and from high to low $2 / 5$ seconds.
\end{abstract}

\section{INTRODUCTION}

According to precision agriculture concepts, agricultural equipment should be able to provide cultivation requirements proportion to the needs for every small part of the field. Therefore, variable rate is a novel technology for seed drills to vary seeding rate in different areas of a field based on predefined maps.

Thus, current seed drills with fixed rate for converting to a variable rate machine require some mechanical changes via applying control mechanisms. Hand changing seed rate during the movement and when the machine is distributing seeds on the field is time-consuming; consequently, in the transition Zone, it does not apply from one rate to another at the field rate at the desired rate. The severity of the failure to apply the input correctly depends on the characteristics of the control mechanism. One of the most important features of the control mechanism is the response time. To reduce the response time of the control system, the optimal method for changing rate of seeding must be selected.

In seed drills, based on the kind of applied seed metering mechanism, there are two methods in order to change the seeding rate include: changing the length of the cylinder and changing the axis of the mosaic. Bahri (1995) developed a simple control system for changing the axial length of the mosaic to change the seed rate of wheat during the movement.
The control system was made of open loop type and included: battery, switch-on (mounted on the tractor cabin), restrictive switches (mounted on the seed metering system), and linear actuators (mounted on the special lever for changing seeding rate). The response time of the control system was reported to be about 6 seconds for an increase of $20 \mathrm{~kg} / \mathrm{ha}$. To reduce the seed rate, the presence of seeds in the mosaic prevents the movement of the axial length of the mosaic during movement. Therefore, he did not recommend changing the axial length of the mosaic as a method for changing the seed rate during the movement.

By examining the mechanisms available to change the rotational speed of the axis of the linear line, two methods of control can be used: position control and speed control. Maliki et al. (2015) used a pneumatic drill to build a variable rate fertilizer, equipped by a pneumatic operator with gearbox ratios of continuous gear ratio with a linear electric operator. The linear operator changes the position of the gear lever. To send the command to the electric actuator, a program that was written with the LabVIEW graphic software was used. The operator was able to change the application rate of phosphate fertilizer at intervals of $5 \mathrm{~kg} / \mathrm{ha}$.

The control of the axial circle of the mosaic can be made in both open and closed loops. In the open loop control system (Figure. 1 ), there is no feedback signal and no modification of the command signal based on the feedback. Inaccuracy is due to the inability of the system to regulate the applied rate dynamically

\footnotetext{
* Corresponding author
} 
in a situation where changes in load, operator wear and tear occur under applied conditions.

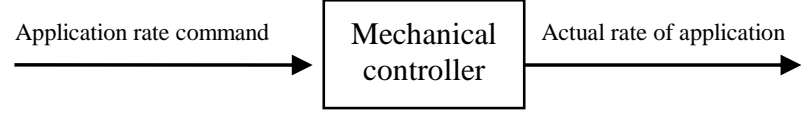

Figure 1 - Open loop control system.

In the closed loop system (Fig. 2), the feedback signal is compared with the command signal and the error rate of the applied input is calculated. Error is used to set the command signal, and therefore the applied rate approaches the target rate closer and the error becomes closer to zero

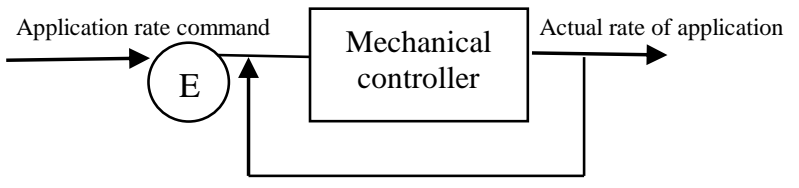

Figure 2 - closed loop control system

Bahri (1995) developed a simple control system for changing the axial direction of the wheel to change the seed rate during the movement. The system was open-loop and includes: 1) batteries, 2) rheostat as a control unit (in the cabin of the tractor installed), and 3) A Permanent magnet engine 12V DC transmission (the axis distributor installed Was). The results showed that this control system could be suitable for specific fielding. According to the literature review, the aim of this study was to select the best CCS control system for linear shifting of the work from the non-invariant rate to the fixed rate.

\section{MATERIALS AND METHODS}

\subsection{Seed drill specifications}

Hassia seed drill that equipped with 19 seed openers is one of the most commonly used drills in Iran. The seed metering system in this machine is the fluted roller which takes power from the ground wheel of the machine by a mechanism of chain drive and gearbox. The gearbox allows the seeding practice to perform with different seed rates at a constant forward speed using a cam and follower mechanism, with the help of one-way bearings. , .

\subsection{The suggested methods for linear changes of the Hassia's work from uniform rate to variable rate}

A. Using the idea of linear operator and gearbox with continuous gear ratios: Due to the existence of a gearbox with continuous gear ratios on the Hassia seed drill, it is possible to control the seed loss control system by controlling the position of the shift lever on this line. This system consists of a linear electric actuator and a gearbox with continuous gear ratios (Figure 3). In fact, this linear actuator is a DC motor and a power screw, which prevents screw rotation using the bearings, and the screw only has a reciprocating motion and, as a result, the rotary motion of the engine is converted into a reciprocating motion. The other part of this system is a shift lever that moves around an arc. This arc, which moves from the beginning to the end, equal to 43.5 degrees of leverage, is divided into 90 equal parts.

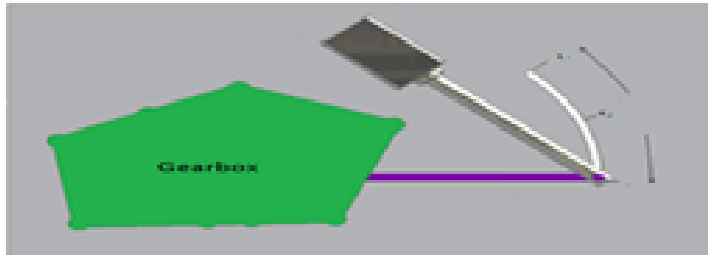

Figure 3 - Shifting the gear and then changing the seed rate using the electric operator idea.

B. Using variable belt wheel: The system is consist of a belt drive system, whose effective diameter can be changed (Figure 4 ), and hence the conversion ratio between the two belt wheels can be changed. Due to the fixed length of the strap, reducing the diameter of a belt wheel will increase the diameter of the other belt wheel. By moving the two half-wheel straps relative to each other, a wide range of conversion ratios can be obtained [4]

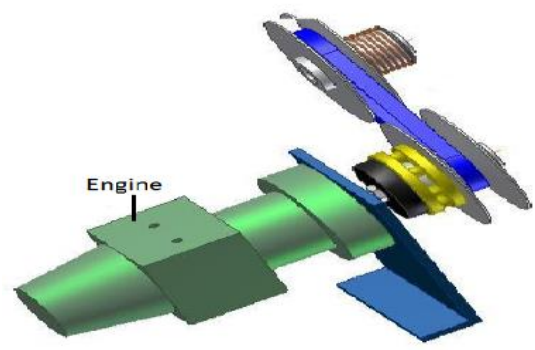

Figure 4: Changing the rotational speed of seed metering drive shaft using the belt mechanism wheel

C. Using magnetic clutch and chain drive: In this method, the multi-wheel chains, which are mounted between the propeller axis and the propeller axis, are used for different planting rates (Figure 5). All wheel chains are free of charge on the axis of the vehicle. In this method, using an electric clutch, according to the desired seed rate, one of the chain wheels is locked on the axis of the clutch [3].

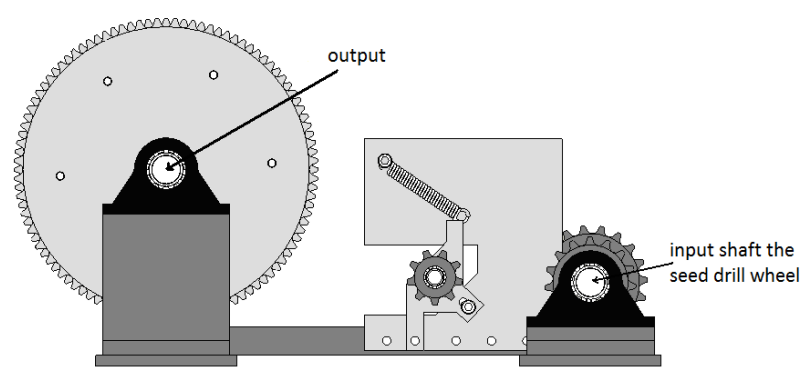

Figure 5: Changing the rotational speed of seed metering drive shaft using the magnetic clutch and a chain wheel.

D) The rotary speed of the wheel in the seed drills is transmitted to the sun gear in a planetary gearbox. The power shaft of the seed metering mechanism is connected to the carrier and to change the metering system speed, the internal gear speed changes using a DC engine. (Figure 6). For control of this loop system, the feedback is taken from the velocity of the loop. 


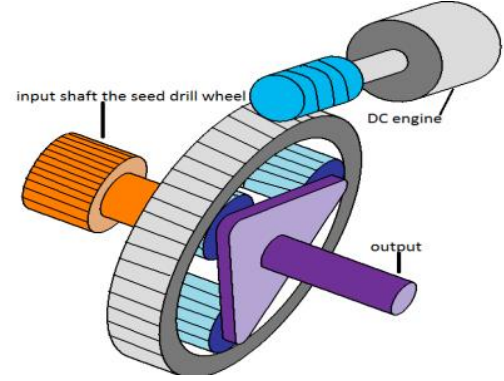

Figure 6 - Changing the rotational speed of seed metering drive shaft using the solar gearbox

E) using an electric engine

In this method, a DC engine with a gearbox is used to move the axis directly. A speed controller is required to change the engine speed (Figure 7). Due to the fact that the rotation speed of the axis of rotation is independent of the linear velocity of the work, the speed of the linear wheel must be reversed. In order to control the system of the ring and the load turbulences do not affect the velocity of the axis of the axis, it must be taken by a speed feedback axis encoder.
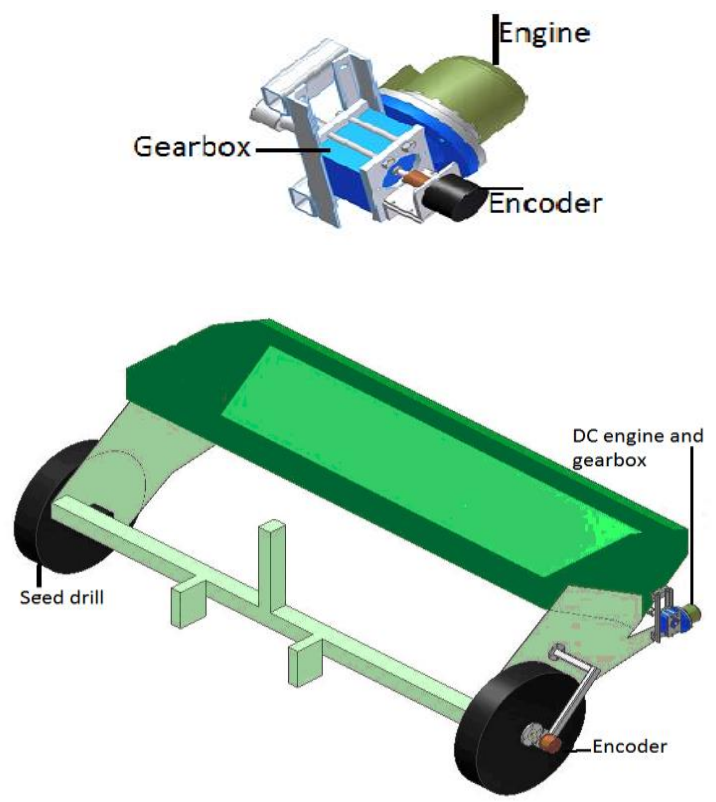

Figure 7 - Changing the rotational speed of seed metering drive shaft using the DC engine and gearbox with a constant gear ratio.

F) Examining the advantages and disadvantages of proposed methods

In Table 1, different proposed designs are compared to select the best plan. The use of an electric linear actuator and a gearbox with a continuous gear ratio is not difficult to construct, and it is only necessary to install a linear operator and an encoder on a line of work in such a way that the degrees of freedom of the system are preserved. Due to the presence of leaks in mechanical systems, lever control is difficult.

Using variable-speed belt wheels is difficult because of the high cost and difficulty of making wheel rims and the purchase of equipment such as a hydro-engine and it is difficult to slip on the control belt. The use of a magnetic clutch due to the large number of occupants and the impossibility of having different continuous rates of planting is more suitable for the rows of tasks. The use of a sun gearbox with two inputs is not acceptable due to the high cost and manufacturing of gearboxes. The final design, which uses a DC engine with a constant gear ratio is more suitable. This plan does not require construction of components and the possibility of different seeding rates. It needs minimum changes in the seed drills and low costs compared to other designs.

Table 1- Reviewing proposed projects

\begin{tabular}{|c|c|c|c|c|c|c|}
\hline $\begin{array}{l}\text { The } \\
\text { propos } \\
\text { ed rate } \\
\text { change } \\
\text { system }\end{array}$ & $\begin{array}{l}\text { different } \\
\text { rates } \\
\text { Possibility }\end{array}$ & $\begin{array}{c}\text { Space } \\
\text { occupied by } \\
\text { system } \\
\text { components }\end{array}$ & $\begin{array}{l}\text { The } \\
\text { difficulty of } \\
\text { the control } \\
\text { system }\end{array}$ & $\begin{array}{l}\text { The cost } \\
\text { of the } \\
\text { project }\end{array}$ & $\begin{array}{r}\text { The } \\
\text { difficulty } \\
\text { of } \\
\text { production }\end{array}$ & $\begin{array}{l}\text { Total } \\
\text { points }\end{array}$ \\
\hline A & Good & Good & weak & Good & Good & 13 \\
\hline B & Good & weak & weak & weak & Very weak & 6 \\
\hline C & Very weak & weak & Good & Good & Good & 10 \\
\hline D & Good & Good & Good & Medium & weak & 12 \\
\hline E & Very Good & Good & Good & Good & Good & 16 \\
\hline
\end{tabular}

\subsection{Requirements for variable rate control system}

The variable rate control system should read the tractor's position from the GPS and the speed of the seed drill ground wheel from the attached encoder. This information is compared with the information in the computer representing the circumference of the moss thereby indicating the amount of seed per unit area in terms of position (base map). The seed rate is compared to the instantaneous rate at each location, and the appropriate command, which is an 8-bit number, is sent through the computer's parallel bus to the engine speed control circuit

\subsection{Specification of the final design}

After selecting the final design, in order to design different components, the required torque for rotation of the axis of the engine was obtained by measuring a torque meter of $10 \mathrm{~nm}$. Considering the maximum wheat planting rate and tractor speed at planting time of $350 \mathrm{~kg} / \mathrm{ha}$ and $10 \mathrm{~km} / \mathrm{h}$, the maximum speed of the axis of the coupling was $50 \mathrm{rpm}$. So, the power required to rotate the $\mathrm{V}$-axis was $52.5 \mathrm{~W}$. The rotational speed of the DC engines is often high, and the gearbox must be used to provide the rotating speeds required by the drive axle. In this research, the snail gear box was selected with a reduction in gear ratios of 1:40. Due to the low efficiency of the coil reducer gear box, the DC engines of the electric scooter engine were selected. This DC engine has a power output of $250 \mathrm{~W}$ and a voltage of $24 \mathrm{~V}$ and a maximum starting current of $13.5 \mathrm{amps}$. It has a permanent magnet and has four poles. The maximum engine torque is between 2600 and $2850 \mathrm{rpm}$ at between $0 / 84$ and $0,92 \mathrm{n} / \mathrm{m}$. Due to the gear ratio and engine speed ratios, the rotary speed of the axis is adjustable from 0 to $65 \mathrm{rpm}$ and can be used to plant other seeds. 


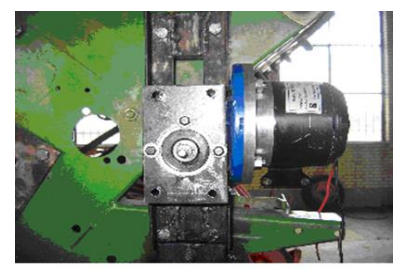

b

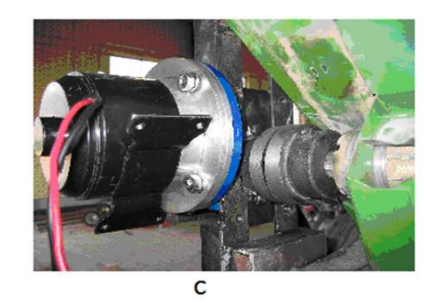

Figure 8. Different views of the DC engine and the gearbox mounted on the Hassia seed drill; a) The engine, b) the gearbox, and c) the coupling of the gearbox axle to the axis of the gearbox

The encoder is connected to the ATONIX 1 gearbox's output shaft and sends 2500 pulses per revolution of rotation and feeds 12 to $24 \mathrm{~V}$. The encoder is connected to the seed drill wheel of the Tabriz-e-Pajhu company and sends 200 pounds for each turning cycle and feeds $5 \mathrm{~V}$ (Figure 2).
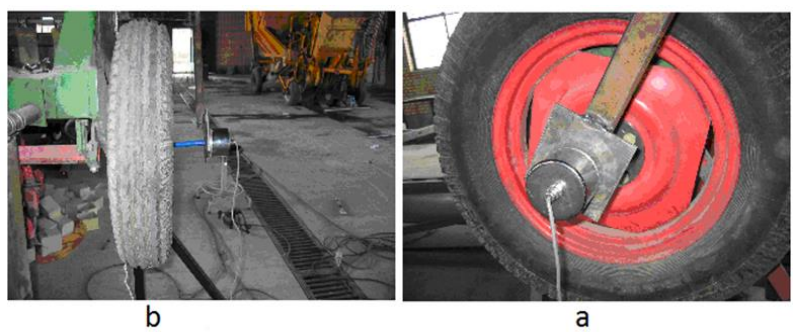

Figure 9. Different views of the encoder mounted on the Seed drill

2.5 Evaluation of the variable rate plant

The evaluation steps included:

1. Low rate seeding

2. High-rate seeding

3. Seeding in variable rate (from low to high rate)

4. Seeding in variable rate (from high to low rate)

Each of the four above mentioned steps was performed in three replicates and a total of 12 test steps. These tests were performed to measure the seed precision in two fixed and variable rates. In order to collect the output seeds from various linear laminates, the plastic sheet expanded $12 \mathrm{~m}$ long and $3 \mathrm{~m}$ wide. Seed boxes with dimensions of $10 \times 14 \times 14 \mathrm{~cm}$ were placed along 7 linear rows of rows (rows not in the trackside paths and linear wheels). Boxes in rows were 1 meter (Figure 10). To measure the response time, changing the linear rate of variable rate work, after passing through the first row of boxes and tangents to the boxes in the first column of the order of the seed rate change command was applied to the control system.

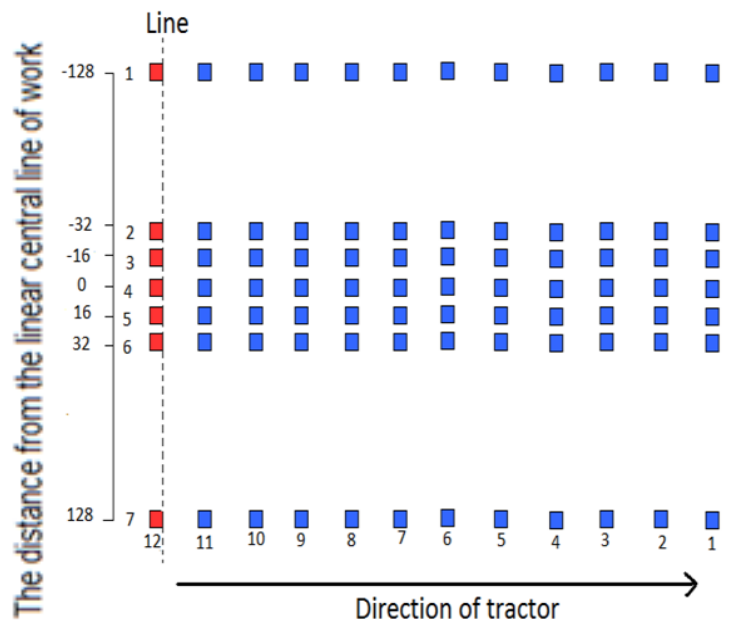

Figure 10. Arrangement of seed collection matrix and command line location to change the seed rate

The maximum wheat planting rate was $350 \mathrm{~kg}$ ha- 1 for indicating the capability of the plant. According to the standard of evaluation of variable rate devices, two high seed rates ( $75 \%$ maximum sowing rate) and low seeding rates (25\% maximum planting rate) with the orders of 262.5 and $87.5 \mathrm{~kg} /$ ha were selected and the speed of the movement was $3.6 \mathrm{~km} /$ ha [7].

\section{RESULTS AND DISCUSSION}

Assessment capability of control systems on the linear HSS performed using A DC motor that applied to select rotational speed of input axis in engine that rotates seed metering mechanism. This control system was included: 1) a $250 \mathrm{~W}$ DC engine with a gearbox with a constant gear ratio, 2) two encoders (one for sensing the linear actuator speed and the other for sensing the engine speed), 3) GPS receiver, 4) DC engine controller, and 5) a portable computer for data collection. Based on the user communication program written under the Visual Basic software, it is possible to control the seed rate at the right moment. According to Figure12 (a), the transmission delay distance is from a high seeding rate of $2.7 \mathrm{~m}$. The starting point of the change in the rate is $3.5 \mathrm{~m}$ and its end point is $6.2 \mathrm{~m}$, the transmission distance is $5.2 \mathrm{~m}$. As a result, due to the speed of the tractor, which is $3.6 \mathrm{~km} / \mathrm{h}(1 \mathrm{~m} / \mathrm{s})$, the response time of the variable rate system in the transfer rate from 262.5 to 87.5 $\mathrm{kg} / \mathrm{ha}$ is 5.2 seconds.

Figure 12 (b) indicates that the transfer delay distance is from the low seed rate to a high rate of $-0.5 \mathrm{~m}$, which means we start moving at a rate higher than $87.5 \mathrm{~kg} / \mathrm{ha}$. The starting point is the change in the place at $-0.5 \mathrm{~m}$ and its end point at $6.84 \mathrm{~m}$. The transmission distance is $7.38 \mathrm{~m}$. Consequently, due to the speed of the tractor, the response time of the variable rate system in the transfer rate from 78.5 to $262.5 \mathrm{~kg} /$ ha is 7.38 seconds. Increasing the response time of the variable rate control system in the transmission of low to high rates is far higher than low to high due to increased engine torque because the engine must provide more torque and therefore more time to transmit the required rate. On the seeding rate curve from high to low, the S-shape equation with the following formula and coefficient of determination (R2), fitted to 0.91

$$
\widehat{y}=262.5-\frac{175}{1+e^{(-2.293 x+10.58)}}
$$


On the seeding rate curve from low to high, the S-equation fitted with the following relation and coefficient of determination (R2), 0.96

$$
\widehat{y}=87.5+\frac{175}{1+e^{(-0.8364 x+3.213)}}
$$

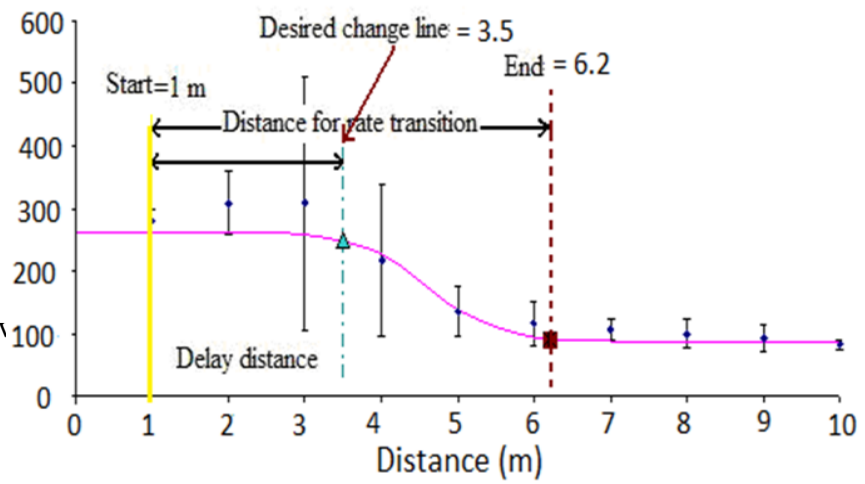

(a)

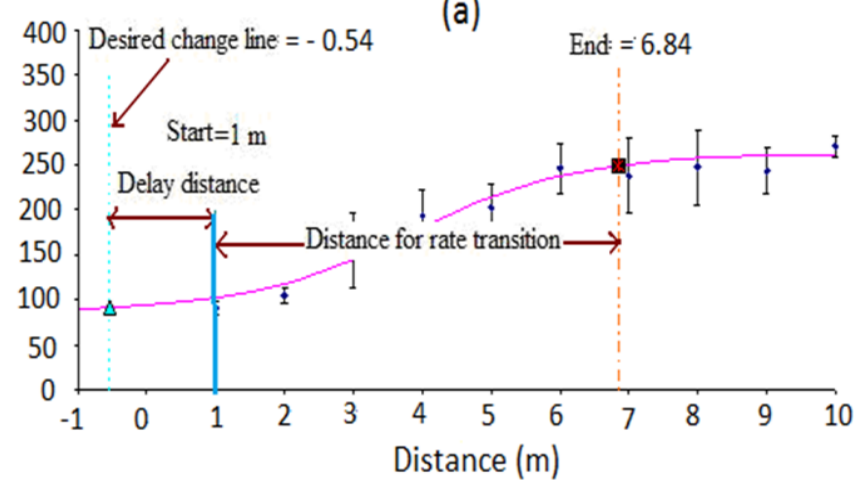

(b)

Figure 11 - Response time charts for the variable rate control system, a) change from seed rate of 262.5 to $87.5 \mathrm{~kg} / \mathrm{ha}$; and b) change from seeding rate of 87.5 to $262.5 \mathrm{~kg} / \mathrm{ha}$

\section{REFERENCES}

Anderson, N. W. and D. S. Humburg. 1997. The site-specific management for agricultural systems. PP. 250-251. ASACSSA-SSSA, 677 S, Segoe Rd., Madison, WI 53711, USA.

Gago-Silva, A., 2016. GRASS GIS in Grid Environment. doi.org/10.6084/m9.figshare.3188950.

Bahri, A., K. Von Bargen and D. B. Marx. 1995. Modulating wheat seeding rate for site specific crop management, University of Nebraska, Lincoln.

Drummond, P. E. 2012. Variable rate drive. United State Patent. No. US2002/ 0178981.

Huffmeyer, E. H. 2013. Inclinometer-controlled apparatus for varying the rate of seed population. United State Patent. No. 6640733B2.2017).

Landphair, D. K. 2005. Variable speed drive for agricultural seeding machine. United State Patent. No. US 2005/0257725 A1.
Maleki, M. R., A. M. Mouazen, B. De Ketelaere, H. Ramon and J. De Baerdemaeker. 2015. On-the-go variable-rate phosphorus fertilization based on a visible and near-infrared soil sensor. Biosystem Engineering. v(99: 35-46.

Shearer, S. A., J. P. Fulton, M. W. Veal and T. S. Stombaugh. 2015. Procedures for Evaluating Variable-Rate Granular Material Application Accuracy. ASAE PM-54 Draft Standard. 